\title{
KINETIC MODELLING OF ESCHERICHIA COLI INACTIVATION IN A PHOTOCATALYTIC WALL REACTOR
}

Javier Marugán ${ }^{\mathrm{a}}$, Rafael van Grieken ${ }^{\mathrm{a}}$, Cristina Pablos ${ }^{\mathrm{a}}$, M. Lucila Satuf ${ }^{\mathrm{b}}$, Alberto E. Cassano ${ }^{\mathrm{b}}$, Orlando M. Alfano ${ }^{\mathrm{b}}$.

${ }^{a}$ Department of Chemical and Environmental Technology, ESCET, Universidad Rey Juan Carlos, C/ Tulipán s/n, 28933 Móstoles (Madrid), Spain

Tel: +34 91664 7466, Fax +34 91488 7068, E-mail: javier.marugan@ urjc.es

${ }^{\mathrm{b}}$ Instituto de Desarrollo Tecnológico para la Industria Química (INTEC), (Universidad Nacional del Litoral-CONICET), CCT Santa Fe. Paraje El Pozo. Colectora de la Ruta Nacional No 168, 3000 Santa Fe, Argentina Tel: +54 342451 1272/73, Fax +54 342451 1087, E-mail: alfano@intec.unl.edu.ar

Published on

Catalysis Today 240 (2015) 9-15.

doi:10.1016/j.cattod.2014.03.055 


\begin{abstract}
A kinetic model of the photocatalytic inactivation of Escherichia coli in an annular wall reactor is presented. The model is based on a reaction scheme that involves a series of events in which bacteria are progressively damaged and eventually led to cell lysis. The model explicitly takes into account radiation absorption effects. Photocatalytic inactivation experiments were carried out in a photoreactor operated in a closed recirculating circuit with a reservoir tank and irradiated with a $6 \mathrm{~W}$ black light lamp situated in the axis of the reactor. Immobilization of $\mathrm{TiO}_{2}$ Aeroxide $\mathrm{P} 25$ has been carried out by the dip-coating procedure onto the inner-tube wall of the annular reactor. Experimental results for different $\mathrm{TiO}_{2}$ layer thicknesses were used to estimate the kinetic parameters of the model. Good agreement between model predictions and inactivation experiments was achieved in the whole range of $\mathrm{TiO}_{2}$ thicknesses studied.
\end{abstract}

KEYWORDS: immobilized catalyst, kinetics, disinfection, titanium dioxide, wall reactor. 


\section{INTRODUCTION}

The provision of safe drinking water is a key issue for human development and has become one of the main concerns of governments and international organizations $[1,2]$. Therefore, research on more efficient purification processes represents a major topic for scientific community. Photocatalysis with titanium dioxide is an effective alternative to conventional water disinfection technologies that employ powerful chemicals such as chlorine compounds [1]. Among the main advantages of photocatalysis, it should be cited: mild reaction conditions, absence of harmful by-products, non-selectivity of $\mathrm{TiO}_{2}$, and the possibility of employing solar radiation to activate the catalyst.

In many studies on water treatment, suspensions of fine $\mathrm{TiO}_{2}$ powder under UV irradiation are employed. However, the applicability of photocatalysis on large scale requires the immobilization of $\mathrm{TiO}_{2}$, in order to avoid the catalyst separation step and to allow carrying out the process in continuous mode. The performance of immobilized catalytic systems is reported to be lower than that of $\mathrm{TiO}_{2}$ slurry reactors in deionised water, apparently due to mass transport limitations and less available catalytic area $[3,4]$. Nevertheless, wall reactors have shown lesser inhibition by the presence of dissolved organic matter when compared with slurry reactors. Besides, immobilized systems have proven to be stable and do not show deactivation after several cycles of reuse, being readily applicable for continuous water treatment systems [5].

Although photocatalysis for water disinfection has been extensively investigated, studies focused on the modeling of the process remain scarce. The mathematical models employed to represent the kinetics of photocatalytic disinfection have been thoroughly reviewed by Dalrymple et al. [6]. The majority of them are empirical, mainly based on conventional, homogeneous chemical disinfection principles which cannot be directly applied to heterogeneous photocatalytic systems. On the other hand, mechanistic models are more 
suitable to predict the performance of real photocatalytic devices under a wide range of operating conditions because they are based on the physical and chemical events that take place in the disinfection process. This kind of models can be classified in: lipid peroxidation models, microbe-catalyst interaction models, series-event and multi-target models.

Maximum interaction between radiation, catalytic surface and microorganisms is the main goal in the design of efficient devices for water disinfection. Therefore, kinetic models that take into account radiation absorption effects and adsorption phenomena between catalyst and bacteria are essential. This work is focused on the kinetic modelling of the photocatalytic inactivation of Escherichia coli based on a proposed reaction scheme with explicit radiation absorption effects. The experiments were carried out in a laboratory scale, annular, wall photoreactor operating in a closed recirculating system. A precise evaluation of the superficial rate of photon absorption for the $\mathrm{TiO}_{2}$ layer, required to model the effect of the radiation absorption on the inactivation reaction rates, is carried out by applying a radiation balance in terms of the net radiation fluxes at the inlet and outlet of the $\mathrm{TiO}_{2}$ layer. The aim of this study is the development of a kinetic model independent of the irradiation conditions, useful for reactor designing or scaling-up purposes. Accurate models could help to predict and optimize the performance of commercial devices, with the consequent economical benefits.

\section{EXPERIMENTAL}

\subsection{Photoreactor}

Photocatalytic experiments were carried out in an annular photoreactor made of borosilicate glass. The reactor is $15 \mathrm{~cm}$ long, with an inner-tube diameter of $3 \mathrm{~cm}$ and an external-tube diameter of $5 \mathrm{~cm}$. It operates in a closed recirculating circuit driven by a centrifugal pump. The system includes a stirred reservoir tank, being the total working 
volume of $1 \mathrm{~L}$. Illumination was provided by a Philips TL 6W black light lamp, with an emission peak centred at $365 \mathrm{~nm}$, placed in the axis of the reactor. The UV-A radiation that arrived at the inner-tube of the reactor, experimentally measured by ferrioxalate actinometry, was $2.72 \times 10^{-6}$ Einstein $\mathrm{s}^{-1}$. The liquid flow rate was set at $2.5 \mathrm{~L} \mathrm{~min}^{-1}$ to ensure good mixing conditions in the photoreactor and a differential conversion per pass. Good aeration conditions were maintained in the reservoir tank to provide the oxygen required for the reaction.

Aeroxide ${ }^{\circledR} \quad \mathrm{P} 25 \quad \mathrm{TiO}_{2}$ (Evonik Industries $\mathrm{AG}$ ) was employed as photocatalyst. Immobilization was carried out by the dip-coating procedure onto the inner-tube wall of the annular reactor. The coating suspension was prepared by adding $150 \mathrm{~g}$ of $\mathrm{TiO}_{2}$ powder in $1 \mathrm{~L}$ of deionized water. The $\mathrm{pH}$ was adjusted at 1.5 with $\mathrm{HNO}_{3}$. Each coating cycle consists of the following steps: immersion of the glass tube into the catalyst suspension, withdrawal at a speed of $0.65 \mathrm{~mm} \mathrm{~s}^{-1}$, oven drying at $110{ }^{\circ} \mathrm{C}$ for $24 \mathrm{~h}$, and calcination at $500{ }^{\circ} \mathrm{C}$ for $2 \mathrm{~h}$. Inactivation experiments were carried out with glass tubes after 1, 2 and 3 coatings cycles.

\subsection{Experimental procedure}

Escherichia coli K-12 strains were provided lyophilized by the Spanish Type Culture Collection (CECT 4624, corresponding to ATCC 23631). Fresh bacterial cultures of around $10^{9}$ Colony Forming Units (CFU) $\mathrm{mL}^{-1}$ of stationary concentration were prepared by inoculation in a Luria-Bertani nutrient medium (Miller's LB Broth, Scharlab) followed by aerobic incubation at $37{ }^{\circ} \mathrm{C}$ under rotary shaking for $24 \mathrm{~h}$. Reacting suspensions were prepared by centrifuging $5 \mathrm{~mL}$ of the liquid culture at $3000 \mathrm{rpm}$ for 15 minutes, rinsing twice the bacteria with $5 \mathrm{~mL}$ of sterile ultra-pure water (Milli-Q ${ }^{\circledR}, 18.2 \mathrm{M} \Omega \mathrm{cm}$ ) and finally diluting $1 \mathrm{~mL}$ of the aqueous $E$. coli suspension to $1 \mathrm{~L}$ to get an initial concentration of viable bacteria

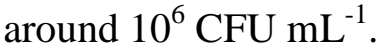


The bacterial suspension was charged in the reservoir tank and the recirculation pump was switched on during 15 minutes. In the meantime, the lamp was switched on outside the reactor to stabilize its emission power and spectrum before the reaction starts. Photocatalytic inactivation was followed by analysing the concentration of viable bacteria by a standard serial dilution method using LB nutrient agar plates (Miller's LB Agar, Scharlab). Eight replicates of each decimal dilution were incubated at $37^{\circ} \mathrm{C}$ for $24 \mathrm{~h}$ before counting the number of bacterial colony forming units (CFU). Key experiments were repeated to test the reproducibility of the disinfection results. Additionally, control experiments were performed to ensure the absence of photolytic reactions (inactivation with UV light alone). No detectable changes in the concentration of viable bacteria were found with the UV lamp on and without the addition of the catalyst.

\section{KINETIC MODEL}

\subsection{Derivation of the kinetic model}

The photocatalytic inactivation of $E$. coli can be modelled in a simple way by a reaction scheme, summarized in Table 1, which involves a series events in which bacteria are progressively damaged and eventually led to cell lysis [7,8]. It includes photocatalyst excitation, recombination of photogenerated charge carriers, electron trapping, and hole trapping steps. Subsequently, the attack of the generated hydroxyl radicals to undamaged $\left(\mathrm{B}_{\mathrm{u}}\right)$, damaged $\left(\mathrm{B}_{\mathrm{d}}\right)$ and inactivated $\left(\mathrm{B}_{\mathrm{i}}\right)$ population of bacteria is proposed. $\mathrm{B}_{\mathrm{pi}}$, with $i=1$ to $n$, represents biological structures and compounds released after the bacterial lysis. The latter steps are not elemental but global stages that involve several radical attacks to the microorganisms. 
The Appendix shows the details of the derivation of the kinetic model and the assumptions considered to obtain the following kinetic expressions:

$$
\begin{aligned}
& r_{u}\left(\frac{\mathrm{CFU}}{\mathrm{s} \mathrm{cm}^{2}}\right)=-\alpha_{1} \frac{\left[\mathrm{B}_{\mathrm{u}}\right]}{\left[\mathrm{B}_{\mathrm{u}}\right]+\alpha_{4}\left[\mathrm{~B}_{\mathrm{d}}\right]+\alpha_{3}\left([\mathrm{~B}]_{0}-\left[\mathrm{B}_{\mathrm{u}}\right]-\left[\mathrm{B}_{\mathrm{d}}\right]\right)}\left\{-1+\sqrt{1+\alpha_{2} e^{a, s}}\right\} \\
& r_{d}\left(\frac{\mathrm{CFU}}{\mathrm{s} \mathrm{cm}^{2}}\right)=\alpha_{1} \frac{\left[\mathrm{B}_{\mathrm{u}}\right]-\alpha_{4}\left[\mathrm{~B}_{\mathrm{d}}\right]}{\left[\mathrm{B}_{\mathrm{u}}\right]+\alpha_{4}\left[\mathrm{~B}_{\mathrm{d}}\right]+\alpha_{3}\left([\mathrm{~B}]_{0}-\left[\mathrm{B}_{\mathrm{u}}\right]-\left[\mathrm{B}_{\mathrm{d}}\right]\right)}\left\{-1+\sqrt{1+\alpha_{2} e^{a, s}}\right\}
\end{aligned}
$$

where $r_{u}$ and $r_{d}$ are the reaction rate for undamaged and damaged bacteria, respectively, [B $\left.\mathrm{B}_{\mathrm{u}}\right]$ and $\left[\mathrm{B}_{\mathrm{d}}\right]$ are the concentration of undamaged and damaged bacteria, $[\mathrm{B}]_{0}$ is the initial concentration of bacteria, $e^{a, s}$ is the superficial rate of photon absorption (SRPA), and $\alpha_{1}, \alpha_{2}$, $\alpha_{3}$, and $\alpha_{4}$ are lumped kinetic parameters. It can be noticed that the proposed kinetic model provides a general rate expression with an explicit dependence of the photon absorption effects on the bacterial inactivation rate.

\subsection{Optical Properties of the catalytic film}

To calculate the rate of photon absorption in the $\mathrm{TiO}_{2}$ film, the optical properties of the coating must be known. To evaluate the volumetric absorption coefficient of film $\left(\kappa_{f}\right)$, the following optical parameters as a function of the wavelength are required: (i) the diffuse transmittance and reflectance of the bare borosilicate glass plates $\left(T_{g}, R_{g}\right)$, and (ii) the diffuse transmittance and reflectance of the coated $\left(\mathrm{TiO}_{2}\right.$ film + glass $)$ borosilicate glass plates $\left(T_{f g}\right.$, $\left.R_{f g}\right)$.

Values of $R$ and $T$ were obtained from experimental measurements determined as a function of wavelength between 340 and $410 \mathrm{~nm}$ in an Optronic OL series 750 spectroradiometer equipped with an OL 740-70 integrating sphere reflectance attachment $[9,10]$. Figure 1 shows the diffuse transmittance results for the glass $\left(T_{g}\right)$ and glass coated with one $\left(T_{f g 1}\right)$, two $\left(T_{f g 2}\right)$ and three $\left(T_{f g 3}\right) \mathrm{TiO}_{2}$ layers [Fig. 1(a)] and the diffuse reflectance 
results for the glass $\left(R_{g}\right)$ and glass coated with one $\left(R_{f g 1}\right)$, two $\left(R_{f g 2}\right)$ and three $\left(R_{f g 3}\right)$ layers [Fig. 1(b)].

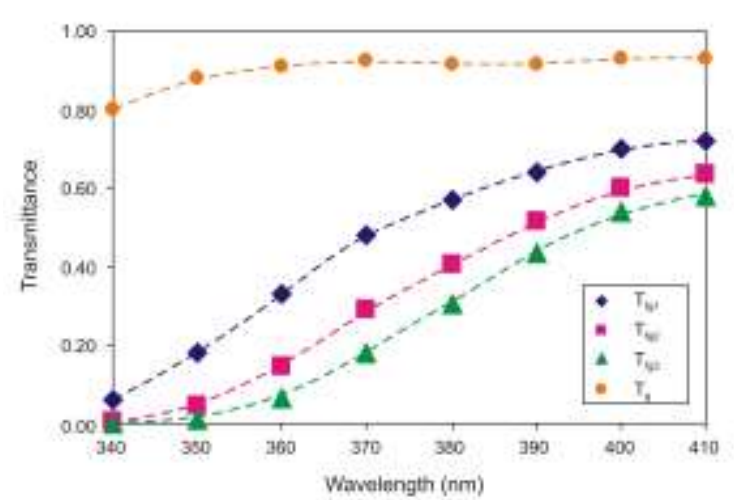

(a)

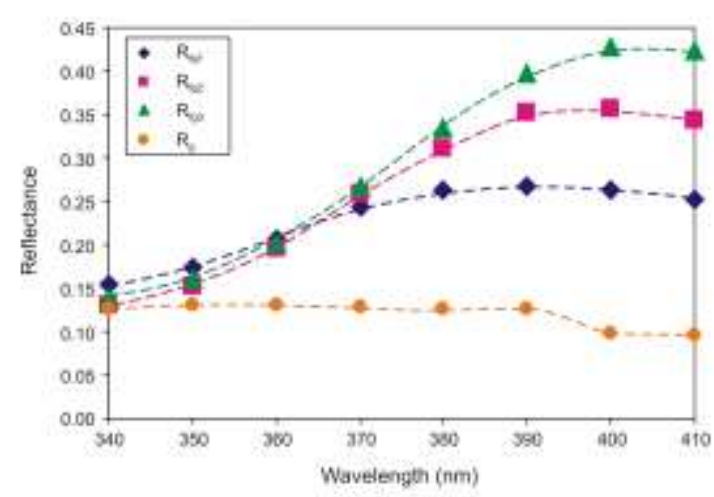

(b)

Figure 1. (a) Diffuse transmittance results as a function of wavelength for the glass $\left(T_{g}\right)$ and glass coated with $1\left(T_{f g l}\right), 2\left(T_{f g 2}\right)$ and $3\left(T_{f g 3}\right)$ layers. (b) Diffuse reflectance results as a function of wavelength for the glass $\left(R_{g}\right)$ and glass coated with $1\left(R_{f g 1}\right), 2\left(R_{f g 2}\right)$ and $3\left(R_{f g 3}\right)$ layers.

To assess the fraction of energy absorbed by the coating, the net-radiation (or the raytracing) method, originally derived for multiple parallel layers can be applied [11]. Multiple reflections, absorptions and transmissions of radiation in the layers are taken into account by means of this technique. The mathematical expressions to calculate the fraction of incident energy transmitted $(T)$, reflected $(R)$ and absorbed $(A)$, are given by the expressions:

$$
\begin{aligned}
& R_{f g, j}=R_{f, j}+\frac{R_{g} T_{f, j}^{2}}{1-R_{f, j} R_{g}} \\
& T_{f g, j}=\frac{T_{f, j} T_{g}}{1-R_{f, j} R_{g}} \\
& A_{f g, j}=1-T_{f g, j}-R_{f g, j}
\end{aligned}
$$

Here $f, g$ and $f g$ represent film, glass and film + glass optical properties, respectively; the subindex $j$ corresponds to a $\mathrm{TiO}_{2}$ film with $j=1,2$ or 3 layers. To simplify the 
nomenclature, the subscript $\lambda$ indicating the wavelength of each optical property was omitted. From Eqs. (3) and (4), the following expressions can be derived to compute the fraction of incident energy transmitted, reflected and absorbed by the film of $\mathrm{TiO}_{2}$ :

$$
\begin{aligned}
& R_{f, j}=\frac{R_{f g, j} T_{g}^{2}-T_{f g, j}^{2} R_{g}}{T_{g}^{2}-R_{g}^{2} T_{f g, j}^{2}} \\
& T_{f, j}=\frac{T_{f g, j}}{T_{g}}\left(1-R_{f, j} R_{g}\right) \\
& A_{f, j}=1-T_{f, j}-R_{f, j}
\end{aligned}
$$

Finally, the volumetric absorption coefficient of the $\mathrm{TiO}_{2}$ film was computed by

$$
\kappa_{f}=-\frac{\ln \left(1-A_{f, j}\right)}{\delta_{j}}
$$

where $\delta_{j}$ is the average thickness of the film with $j$ layers of $\mathrm{TiO}_{2}$. The film thickness for each one of the three $\mathrm{TiO}_{2}$ layers was estimated from the average of ten Scanning Electron Microscopy (SEM) micrographs of the inner-tube glass wall [11]. From these analysis, it has been determined that $\delta_{1}=0.75 \pm 0.1 \mu \mathrm{m}, \delta_{2}=1.1 \pm 0.2 \mu \mathrm{m}$ and $\delta_{3}=1.5 \pm 0.2 \mu \mathrm{m}$. It is important to note that $\kappa_{f}$ is independent of the film thickness.

Figure 2 shows the results of the spectral distribution of the volumetric absorption coefficient of the $\mathrm{TiO}_{2}$ film computed with Eqs. (6) to (9). The normalized spectral distribution of the lamp output power, provided by the lamp manufacturer, is also plotted in the figure. 


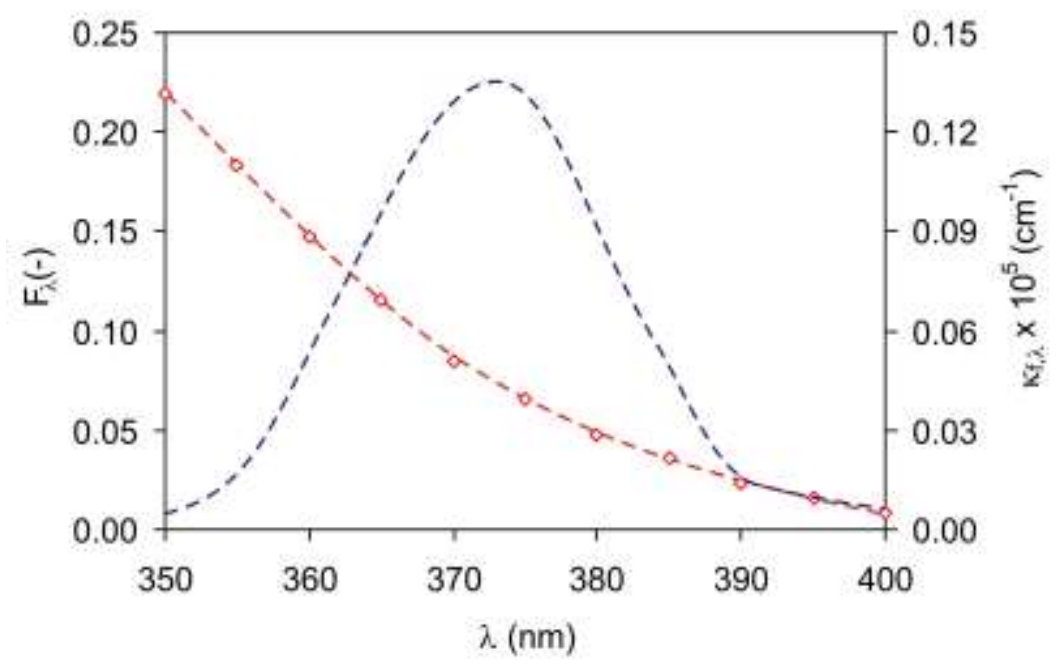

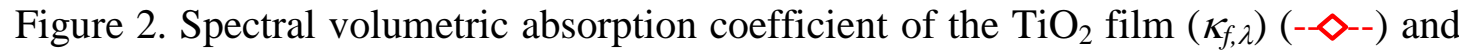
normalized spectral distribution of the lamp output power $\left(\mathrm{F}_{\lambda}\right)(----)$.

\section{3. $\quad$ Superficial Rate of Photon Absorption}

The spectral SRPA in the $\mathrm{TiO}_{2}$ layer can be calculated by a radiation balance in terms of the net radiation fluxes at the inlet $(x=0)$ and outlet $\left(x=\delta_{j}\right)$ of the layer (Figure 3):

$$
e_{\lambda, j}^{a, s}=q_{n, \lambda}^{+}(0)-q_{n, \lambda}^{-}(0)-q_{n, \lambda}^{+}\left(\delta_{j}\right)=q_{n, \lambda}^{+}(0)\left[1-R_{f, \lambda, j}-\frac{q_{n, \lambda}^{+}\left(\delta_{j}\right)}{q_{n, \lambda}^{+}(0)}\right]
$$

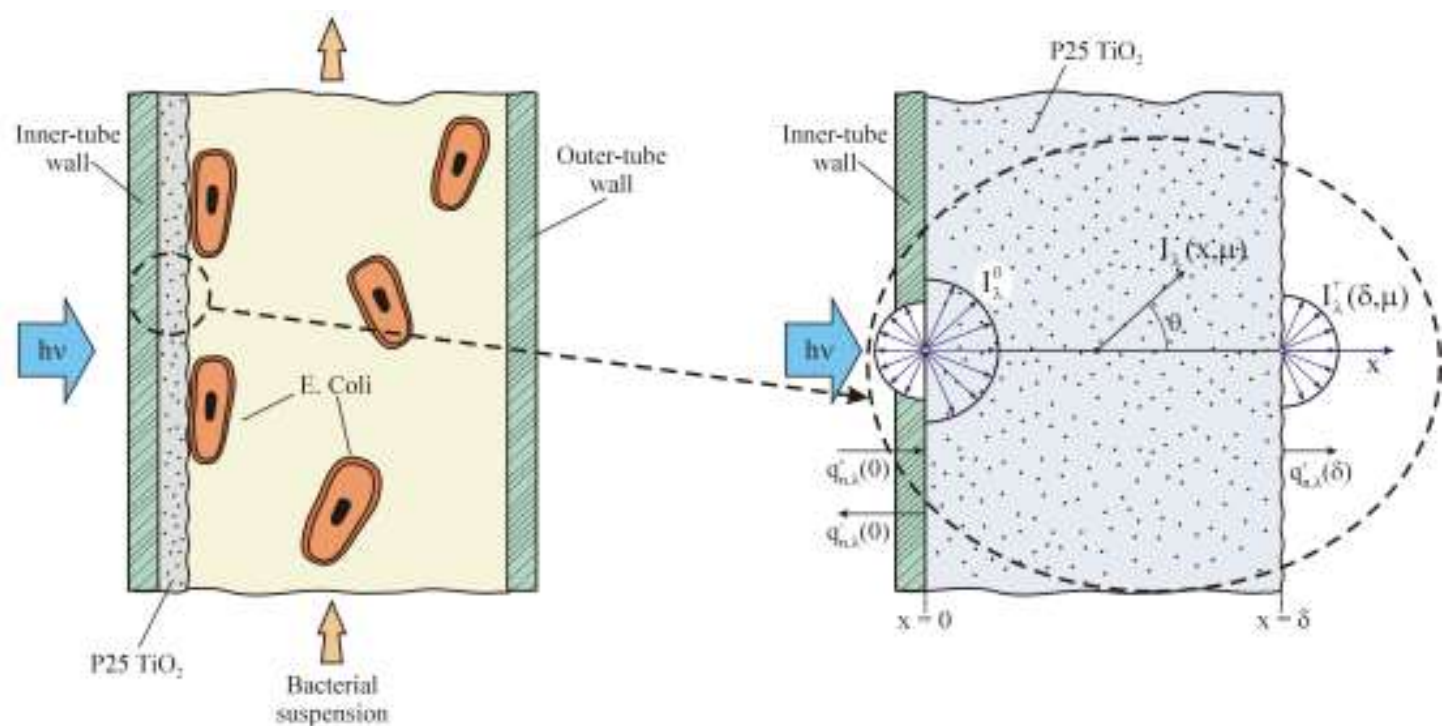


Figure 3. Scheme of the radiation balance in the $\mathrm{TiO}_{2}$ layer.

To evaluate the ratio $\frac{q_{n, \lambda}^{+}\left(\delta_{j}\right)}{q_{n, \lambda}^{+}(0)}$ for any thickness of the $\mathrm{TiO}_{2}$ layer, the Radiative Transfer Equation (RTE) can be applied to the $\mathrm{P} 25 \mathrm{TiO}_{2}$ film irradiated with diffuse radiation. Thus,

$$
\begin{aligned}
& \mu \frac{d I_{\lambda}}{d x}+\kappa_{f, \lambda} I_{\lambda}=0 \\
& I_{\lambda}(O, \mu)=I_{\lambda}^{O}
\end{aligned}
$$

where $I_{\lambda}$ is the spectral radiation intensity and $\mu$ the direction cosine of the ray for which the RTE is written $(\mu=\cos \theta)$. Equations (11) and (12) are solved and then introduced in the mathematical expression of the net radiation flux as a function of position $x$. Thus,

$$
\begin{aligned}
& I_{\lambda}(x, \mu)=I_{\lambda}^{0} \exp \left(-\frac{\kappa_{f, \lambda}}{\mu} x\right) \\
& (13) \\
& q_{n, \lambda}^{+}(x)=2 \pi I_{\lambda}^{0} \int_{0}^{l} \exp \left(-\frac{\kappa_{f, \lambda}}{\mu} x\right) \mu d \mu=2 q_{n, \lambda}^{+}(0) \int_{0}^{l} \exp \left(-\frac{\kappa_{f, \lambda}}{\mu} x\right) \mu d \mu
\end{aligned}
$$

Introducing Eq. (14) into Eq. (10) and integrating the result over all the useful wavelengths, the final expression of the SRPA is obtained:

$$
e_{j}^{a, s}=\sum_{\lambda} e_{\lambda, j}^{a, s}=\frac{P_{a c t}}{A_{i r r}} \sum_{\lambda} F_{\lambda}\left[1-R_{f, \lambda, j}-2 \int_{0}^{l} \exp \left(-\frac{\kappa_{f, \lambda}}{\mu} \delta_{j}\right) \mu d \mu\right]
$$

where $P_{a c t}$ is the total radiation power measured from potassium ferrioxalate actinometry experiments $\left(2.72 \times 10^{-6}\right.$ einstein $\left.\mathrm{s}^{-1}\right)$ and $A_{\text {irr }}$ the irradiated area $\left(141.4 \mathrm{~cm}^{2}\right)$. Values of $\kappa_{f, \lambda}$ and $F_{\lambda}$ were reported in a previous section (Figure 2).

Results of the SRPA computed with Eq. (15) for 1, 2 and 3 layers, are: (i) $e_{1}^{a, s}=0.5461$ $\times 10^{-8}$ einstein $\mathrm{cm}^{-2} \mathrm{~s}^{-1}$, (ii) $e_{2}^{a, s}=0.7249 \times 10^{-8}$ einstein $\mathrm{cm}^{-2} \mathrm{~s}^{-1}$, and (iii) $e_{3}^{a, s}=0.8987 \times 10^{-8}$ einstein $\mathrm{cm}^{-2} \mathrm{~s}^{-1}$. 


\section{RESULTS AND DISCUSSION}

Once the values of the SRPA for the different $\mathrm{TiO}_{2}$ layers have been computed, and the inactivation reaction rates for undamaged and damaged bacteria have been derived, they can be used to solve the mass balances of the photocatalytic wall reactor. Assuming that: (i) the system is perfectly mixed, (ii) there are no mass transport limitations, (iii) the conversion per pass in the annular reactor is differential, and (iv) parallel dark reactions are neglected, the mass balances and the initial conditions of undamaged and damaged bacteria in the storage tank are given by:

$$
\begin{aligned}
& \frac{d\left[\mathrm{~B}_{\mathrm{u}}\right]}{d t}=-\frac{A_{\text {irr }}}{V_{T}} \alpha_{1} \frac{\left[\mathrm{B}_{\mathrm{u}}\right]}{\left[\mathrm{B}_{\mathrm{u}}\right]+\alpha_{4}\left[\mathrm{~B}_{\mathrm{d}}\right]+\alpha_{3}\left([\mathrm{~B}]_{0}-\left[\mathrm{B}_{\mathrm{u}}\right]-\left[\mathrm{B}_{\mathrm{d}}\right]\right)}\left\{-1+\sqrt{1+\alpha_{2} e^{a, s}}\right\} \\
& t=0, \quad\left[\mathrm{~B}_{\mathrm{u}}\right]=[\mathrm{B}]_{0} \\
& \frac{d\left[\mathrm{~B}_{\mathrm{d}}\right]}{d t}=\frac{A_{\text {irr }}}{V_{T}} \alpha_{1} \frac{\left[\mathrm{B}_{\mathrm{u}}\right]-\alpha_{4}\left[\mathrm{~B}_{\mathrm{d}}\right]}{\left[\mathrm{B}_{\mathrm{u}}\right]+\alpha_{4}\left[\mathrm{~B}_{\mathrm{d}}\right]+\alpha_{3}\left([\mathrm{~B}]_{0}-\left[\mathrm{B}_{\mathrm{u}}\right]-\left[\mathrm{B}_{\mathrm{d}}\right]\right)}\left\{-1+\sqrt{1+\alpha_{2} e^{a, s}}\right\} \\
& t=0, \quad\left[\mathrm{~B}_{\mathrm{d}}\right]=0
\end{aligned}
$$

The resolution of the mass balance equations gives the evolution of the E. coli CFU per $\mathrm{mL}$ in the reservoir tank. These values can be compared with the experimental results considering that undamaged and damaged bacteria remain viable and consequently both can be counted by the plating technique.

Using a nonlinear regression algorithm coupled with a Runge-Kutta numerical integration procedure, the kinetic parameters that best represent all the experimental data can be estimated. Table 2 (top) summarizes the values and units of the parameters for the fourparameter kinetic model and the corresponding root mean square error (RMSE). 
Table 2. Estimated kinetic parameters for the 4- and 3-parameter kinetic models

\begin{tabular}{lll}
\hline $\begin{array}{l}\text { 4-PARAMETER } \\
\text { KINETIC MODEL }\end{array}$ & VALUES & UNITS \\
\hline$\alpha_{1}$ & $(6.05 \pm 0.17) \times 10^{1}$ & $\mathrm{~cm} \mathrm{~s}^{-1}$ \\
$\alpha_{2}$ & $(3.18 \pm 0.47) \times 10^{11}$ & $\mathrm{~cm}^{2}$ s einstein $^{-1}$ \\
$\alpha_{3}$ & $(1.07 \pm 0.47) \times 10^{-1}$ & dimensionless \\
$\alpha_{4}$ & $(9.48 \pm 0.63) \times 10^{3}$ & dimensionless \\
RMSE & 0.364 & --- \\
\hline 3-PARAMETER & & \\
KINETIC MODEL & & \\
\hline$\alpha$ & $(3.33 \pm 0.21) \times 10^{7}$ & $\mathrm{~cm}^{2} \mathrm{~s}^{-0.5}$ einstein \\
& & dimensionless \\
$\alpha_{3}$ & $(1.05 \pm 0.21) \times 10^{-1}$ & dimensionless \\
$\alpha_{4}$ & $(2.62 \pm 0.60) \times 10^{3}$ & --- \\
RMSE & 0.346 & \\
\hline
\end{tabular}

It should be noted that the product of the kinetic parameter $\alpha_{2}$ with $e^{a, s}$ for 1,2 or 3 layers is much higher than 1 . Therefore, the simplified kinetic expressions, detailed in the Appendix for cases under high levels of irradiation, can be employed. This approximation leads to a model with only three kinetic parameters: $\alpha, \alpha_{3}$ and $\alpha_{4}$. Accordingly, the mass balances for the three-parameter kinetic model can be expressed as follows:

$$
\begin{aligned}
& \frac{d\left[\mathrm{~B}_{\mathrm{u}}\right]}{d t}=-\frac{A_{i r r}}{V_{T}} \alpha \frac{\left[\mathrm{B}_{\mathrm{u}}\right]}{\left[\mathrm{B}_{\mathrm{u}}\right]+\alpha_{4}\left[\mathrm{~B}_{\mathrm{d}}\right]+\alpha_{3}\left([\mathrm{~B}]_{0}-\left[\mathrm{B}_{\mathrm{u}}\right]-\left[\mathrm{B}_{\mathrm{d}}\right]\right)} \sqrt{e^{a, s}} \\
& \frac{d\left[\mathrm{~B}_{\mathrm{u}}\right]}{d t}=\frac{A_{i r r}}{V_{T}} \alpha \frac{\left[\mathrm{B}_{\mathrm{u}}\right]-\alpha_{4}\left[\mathrm{~B}_{\mathrm{d}}\right]}{\left[\mathrm{B}_{\mathrm{u}}\right]+\alpha_{4}\left[\mathrm{~B}_{\mathrm{d}}\right]+\alpha_{3}\left([\mathrm{~B}]_{0}-\left[\mathrm{B}_{\mathrm{u}}\right]-\left[\mathrm{B}_{\mathrm{d}}\right]\right)} \sqrt{e^{a, s}}
\end{aligned}
$$

The corresponding initial conditions of these ordinary differential equations are given by Eqs. (17) and (19). Using again the nonlinear regression algorithm coupled with a RungeKutta numerical integration procedure, the new parameter values of the three-parameter kinetic model that best represent all the experiments can be evaluated. Table 2 (bottom) gives 
the values of these kinetic parameters and the corresponding RMSE. Note that similar results of the RMSE are found for both kinetic models. Consequently, the three-parameter kinetic model has been chosen to represent the model results.

Figure 4 shows the experimental data of the CFU $\mathrm{mL}^{-1}$ of $E$. coli in water for one, two and three $\mathrm{TiO}_{2}$ coatings (square, circle and triangle symbols) and the simulation results of the three-parameter kinetic model (solid lines).

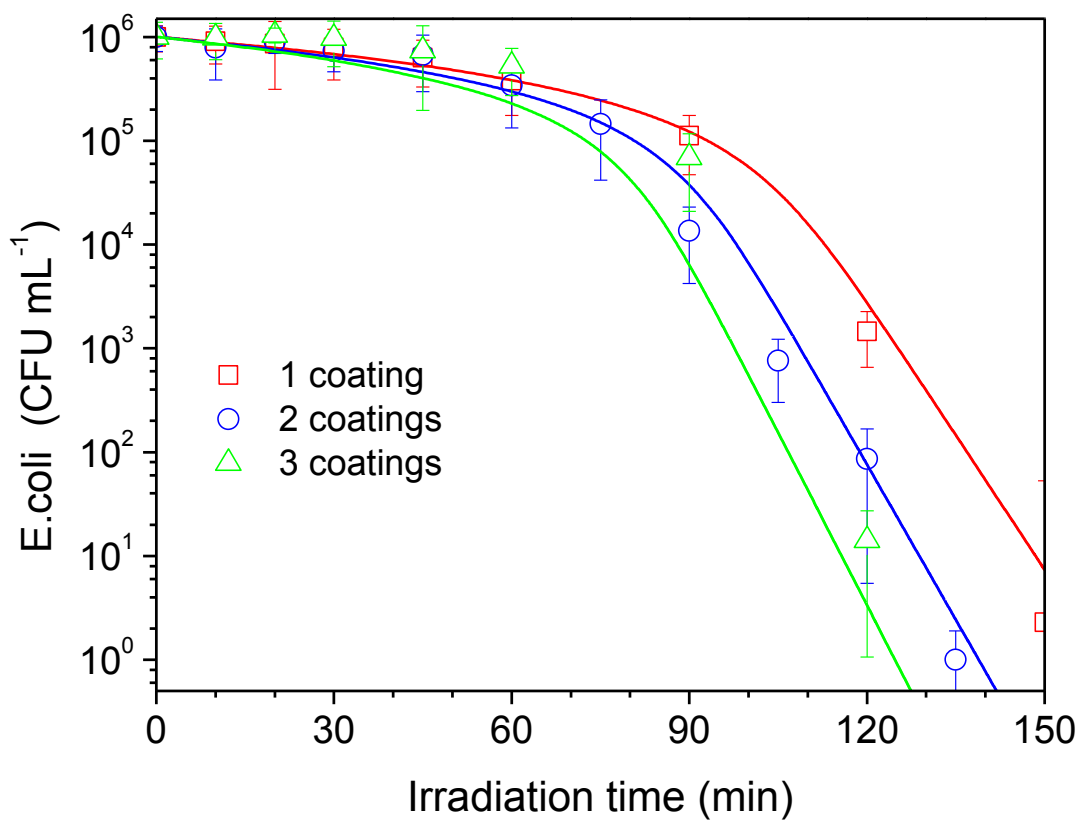

Figure 4. Experimental and three-parameter kinetic model results of the photocatalytic inactivation of $E$. coli with increasing $\mathrm{TiO}_{2}$ layer thickness.

The developed kinetic model shows good agreement with the experimental results of photocatalytic inactivation of bacteria in the whole range of $\mathrm{TiO}_{2}$ layer thicknesses. Moreover, the model is able to represent the initial delays ("shoulders"), the log-linear regions and the absence of "tails" at the end [12].

It should be also noted that when increasing the number of coatings, an increase in the bacterial inactivation activity is observed. However, the activity with three coatings was only 
slightly higher than that with two coatings. For this reason, a higher number of coatings was not investigated in this work.

\section{CONCLUSIONS}

The photocatalytic inactivation of Escherichia coli studied has been modelled by means of a reaction scheme that involves the explicit radiation absorption of the titanium dioxide layer and a series events reaction scheme in which bacteria are progressively damaged and eventually led to cell lysis. The kinetic model has been validated by experimental data obtained in an annular wall photoreactor operating in a closed recirculating system and irradiated with a black light lamp placed in the reactor axis.

The values obtained for the kinetic parameters can be considered independent of the irradiation conditions and reactor configuration. Therefore, the model could be used in a predictive way for designing and scaling-up of water disinfection devices.

\section{ACKNOWLEDGMENTS}

The authors gratefully acknowledge the financial support of the Spanish Ministry of Economy and Competitiveness (MINECO) through the project EMBIOPHOTO (CTM201129143-C03-01) and Comunidad de Madrid through the program REMTAVARES (S2009/AMB-1588). Also, they acknowledge the financial support from the Universidad Nacional del Litoral, Agencia Nacional de Promoción Científica y Tecnológica, and Consejo Nacional de Investigaciones Científicas y Técnicas of Argentina. Cristina Pablos acknowledges Ministerio de Ciencia e Innovación for the FPU grant (AP2008-04567). 


\section{REFERENCES}

[1] S. Malato, P. Fernández-Ibáñez, M.I. Maldonado, J. Blanco, W. Gernjak, Catal. Today 147 (2009) 1-59.

[2] D.M.A. Alrousan, P.S.M. Dunlop, T.A. McMurray, J.A. Byrne, Water Res., 43 (2009) 4754.

[3] P. Fernandez, J. Blanco, C. Sichel, S. Malato, Catal. Today 101 (2005) 345-352.

[4] D. Gumy, A.G. Rincón, R. Hajdu, C. Pulgarin, Sol. Energy 80 (2006) 1376-1381.

[5] C. Pablos, R. van Grieken, J. Marugán, B. Moreno. Catal. Today 161 (2011) 133-139.

[6] O.K. Dalrymple, E. Stefanakos, M.A. Trotz, D.Y. Goswami, Appl. Catal. B: Environ. 98 (2010) 27-38.

[7] J. Marugán, R. van Grieken, C. Sordo, C. Cruz, Appl. Catal. B: Environ. 82 (2008) 27-36. Corrigendum: Appl. Catal. B: Environ. 88 (2009) 582-583.

[8] J. Marugán, R. van Grieken, C. Pablos, M.L. Satuf, A.E. Cassano, O.M. Alfano, Appl. Catal. B: Environ. 102 (2011) 404-416.

[9] M.L. Satuf, R.J. Brandi, A.E. Cassano, O.M. Alfano, Ind. Eng. Chem. Res. 44 (2005) 6643-6649.

[10] S.M. Zacarías, M.L. Satuf, M.C. Vaccari, O.M. Alfano, Ind. Eng. Chem. Res. 51 (2012), $13599-13608$.

[11] R. Siegel, J.R. Howell, Thermal Radiation Heat Transfer, 4th ed., Hemisphere Publishing Corp., Bristol, PA, 2002.

[12] R. van Grieken, J. Marugán, C. Sordo, C. Pablos, Catal. Today 144 (2009) 48-54.

[13] G.E. Imoberdorf, H.A. Irazoqui, A.E. Cassano, O.M. Alfano, Ind. Eng. Chem. Res. 44 (2005) 6075-6085. 


\section{Appendix. Derivation of the kinetic model.}

The kinetic model proposed for the photocatalytic inactivation of Escherichia coli suspensions in a wall reactor is based on the reaction scheme summarized in Table 1. The hydroxyl radical attack is considered the main route for the inactivation of bacteria, and the model assumes that photocatalytic reactions occur at the surface of the catalyst among adsorbed bacteria and biological structures. The expressions for the superficial reaction rate for undamaged and damaged bacteria can be represented by

$$
\begin{aligned}
& r_{u}\left(\frac{\mathrm{CFU}}{\mathrm{s} \mathrm{cm}^{2}}\right)=-k_{5}\left[\mathrm{~B}_{\mathrm{u}, \mathrm{ads}}\right][\cdot \mathrm{OH}]^{\ell} \\
& r_{d}\left(\frac{\mathrm{CFU}}{\mathrm{s} \mathrm{cm}^{2}}\right)=k_{5}\left[\mathrm{~B}_{\mathrm{u}, \mathrm{ads}}\right][\cdot \mathrm{OH}]^{\ell}-k_{6}\left[\mathrm{~B}_{\mathrm{d}, \mathrm{ads}}\right][\cdot \mathrm{OH}]^{\ell}
\end{aligned}
$$

By applying the kinetic micro steady state approximation for the concentration of electrons, holes and hydroxyl radicals, the following expressions can be derived:

$$
\begin{aligned}
& {\left[\mathrm{e}^{-}\right]=\frac{r_{g s}}{k_{2}\left[\mathrm{~h}^{+}\right]+k_{3}\left[\mathrm{O}_{2}\right]}} \\
& {\left[\mathrm{h}^{+}\right]=\frac{r_{g s}}{k_{2}\left[\mathrm{e}^{-}\right]+k_{4}\left[\mathrm{H}_{2} \mathrm{O}\right]}} \\
& {[\cdot \mathrm{OH}]^{\ell}=\frac{k_{4}\left[\mathrm{~h}^{+}\right]\left[\mathrm{H}_{2} \mathrm{O}\right]}{\ell k_{5}\left[\mathrm{~B}_{\mathrm{u}, \mathrm{ads}}\right]+\ell k_{6}\left[\mathrm{~B}_{\mathrm{d}, \mathrm{ads}}\right]+\ell k_{7}\left[\mathrm{~B}_{\mathrm{i}, \mathrm{ads}}\right]+\ell \sum_{i=1}^{n} k_{8 i}\left[\mathrm{~B}_{\mathrm{pi}, \mathrm{ads}}\right]}}
\end{aligned}
$$

Introducing Eq. (A.3) into Eq. (A.4), the expression for the hole concentration is obtained: 
$\left[\mathrm{h}^{+}\right]=\frac{k_{3}\left[\mathrm{O}_{2}\right]}{2 k_{2}}\left\{-1+\sqrt{1+\frac{4 k_{2} r_{g s}}{k_{3} k_{4}\left[\mathrm{H}_{2} \mathrm{O}\right]\left[\mathrm{O}_{2}\right]}}\right\}$

Besides, the superficial rate of electron-hole generation is given by [13]:

$r_{g s}=\bar{\Phi} e^{a, s}$

where $e^{a, s}$ represents the superficial rate of photon absorption (SRPA) and $\bar{\Phi}$ is the primary quantum yield averaged over the wavelength range.

From Eqs. (A.5), (A.6) and (A.7), results

$$
[\cdot \mathrm{OH}]^{\ell}=\frac{\alpha_{1}}{k_{5}\left[\mathrm{~B}_{\mathrm{u}, \mathrm{ads}}\right]+k_{6}\left[\mathrm{~B}_{\mathrm{d}, \mathrm{ads}}\right]+k_{7}\left[\mathrm{~B}_{\mathrm{i}, \mathrm{ads}}\right]+\sum_{i=1}^{n} k_{8 i}\left[\mathrm{~B}_{\mathrm{pi}, \mathrm{ads}}\right]}\left\{-1+\sqrt{1+\alpha_{2} e^{a, s}}\right\}
$$

where

$$
\alpha_{1}=\frac{k_{3} k_{4}\left[\mathrm{H}_{2} \mathrm{O}\right]\left[\mathrm{O}_{2}\right]}{2 \ell k_{2}} \quad \text { and } \quad \alpha_{2}=\frac{4 k_{2} \bar{\Phi}}{k_{3} k_{4}\left[\mathrm{H}_{2} \mathrm{O}\right]\left[\mathrm{O}_{2}\right]}
$$

By defining $\bar{k}_{8}$ as

$$
\bar{k}_{8}=\frac{\sum_{i=1}^{n} k_{8 i}\left[\mathrm{~B}_{\mathrm{pi}, \mathrm{ads}}\right]}{\sum_{i=1}^{n}\left[\mathrm{~B}_{\mathrm{pi}, \mathrm{ads}}\right]}=\frac{\sum_{i=1}^{n} k_{8 i}\left[\mathrm{~B}_{\mathrm{pi}, \mathrm{ads}}\right]}{\left[\mathrm{B}_{\mathrm{p}, \mathrm{ads}}\right]}
$$

Then, Eq. (A.8) results

$$
[\cdot \mathrm{OH}]^{\ell}=\frac{\alpha_{1}}{k_{5}\left[\mathrm{~B}_{\mathrm{u}, \mathrm{ads}}\right]+k_{6}\left[\mathrm{~B}_{\mathrm{d}, \mathrm{ads}}\right]+k_{7}\left[\mathrm{~B}_{\mathrm{i}, \mathrm{ads}}\right]+\bar{k}_{8}\left[\mathrm{~B}_{\mathrm{p}, \mathrm{ads}}\right]}\left\{-1+\sqrt{1+\alpha_{2} e^{a, s}}\right\}
$$

Introducing Eq. (A.11) into the superficial rate expression for the undamaged bacteria, the following equation is derived: 
$r_{u}\left(\frac{\mathrm{CFU}}{\mathrm{s} \mathrm{cm}{ }^{2}}\right)=-\frac{\alpha_{1} k_{5}\left[\mathrm{~B}_{\mathrm{u,ads}}\right]}{k_{5}\left[\mathrm{~B}_{\mathrm{u}, \mathrm{ads}}\right]+k_{6}\left[\mathrm{~B}_{\mathrm{d}, \mathrm{ads}}\right]+k_{7}\left[\mathrm{~B}_{\mathrm{i}, \mathrm{ads}}\right]+\bar{k}_{8}\left[\mathrm{~B}_{\mathrm{p}, \mathrm{ads}}\right]}\left\{-1+\sqrt{1+\alpha_{2} e^{a, s}}\right\}$

Assuming that dynamic equilibrium is achieved between bulk and adsorbed concentrations of bacteria and biological structures, the following equations can be written:

$\left[\mathrm{B}_{\mathrm{u}, \mathrm{ads}}\right]=K_{u}\left[\right.$ site $\left._{\mathrm{vac}}\right]\left[\mathrm{B}_{\mathrm{u}}\right]$

$\left[\mathrm{B}_{\mathrm{d}, \mathrm{ads}}\right]=K_{d}\left[\right.$ site $\left._{\mathrm{vac}}\right]\left[\mathrm{B}_{\mathrm{d}}\right]$

$\left[\mathrm{B}_{\mathrm{i}, \mathrm{ads}}\right]=K_{i}\left[\right.$ site $\left._{\mathrm{vac}}\right]\left[\mathrm{B}_{\mathrm{i}}\right]$

$\left[\mathrm{B}_{\mathrm{p}, \mathrm{ads}}\right]=K_{p}\left[\right.$ site $\left._{\mathrm{vac}}\right]\left[\mathrm{B}_{\mathrm{p}}\right]$

Introducing the adsorption equilibrium equations into Eq. (A.12) results

$r_{u}\left(\frac{\mathrm{CFU}}{\mathrm{s} \mathrm{cm}^{2}}\right)=-\frac{\alpha_{1} k_{5} K_{u}\left[\mathrm{~B}_{\mathrm{u}}\right]}{k_{5} K_{u}\left[\mathrm{~B}_{\mathrm{u}}\right]+k_{6} K_{d}\left[\mathrm{~B}_{\mathrm{d}}\right]+k_{7} K_{i}\left[\mathrm{~B}_{\mathrm{i}}\right]+\bar{k}_{8} K_{p}\left[\mathrm{~B}_{\mathrm{p}}\right]}\left\{-1+\sqrt{1+\alpha_{2} e^{a, s}}\right\}$

Assuming that the lysis of the inactivated bacteria $\left[\mathrm{B}_{\mathrm{i}}\right]$ can generate $n$ molecules of organic compounds, $\left[\mathrm{B}_{\mathrm{p}}\right]$ is estimated by:

$\left[\mathrm{B}_{\mathrm{p}}\right]=\sum_{i=1}^{n}\left[\mathrm{~B}_{\mathrm{pi}}\right]=n\left[\mathrm{~B}_{\mathrm{i}}\right]=n\left([\mathrm{~B}]_{0}-\left[\mathrm{B}_{\mathrm{u}}\right]-\left[\mathrm{B}_{\mathrm{d}}\right]\right)$

Substituting Eq. (A.18) into Eq. (A.17) and rearranging, it is obtained:

$r_{u}\left(\frac{\mathrm{CFU}}{\mathrm{s} \mathrm{cm}^{2}}\right)=-\alpha_{1} \frac{\left[\mathrm{B}_{\mathrm{u}}\right]}{\left[\mathrm{B}_{\mathrm{u}}\right]+\alpha_{4}\left[\mathrm{~B}_{\mathrm{d}}\right]+\alpha_{3}\left([\mathrm{~B}]_{0}-\left[\mathrm{B}_{\mathrm{u}}\right]-\left[\mathrm{B}_{\mathrm{d}}\right]\right)}\left\{-1+\sqrt{1+\alpha_{2} e^{a, s}}\right\}$

where

$\alpha_{3}=\left(\frac{k_{7} K_{i}+\bar{k}_{8} K_{p} n}{k_{5} K_{u}}\right) \quad$ and $\quad \alpha_{4}=\frac{k_{6} K_{d}}{k_{5} K_{u}}$ 
Following a similar procedure, the reaction rate for damaged bacteria can be calculated as

$$
r_{d}\left(\frac{\mathrm{CFU}}{\mathrm{s} \mathrm{cm}^{2}}\right)=\alpha_{1} \frac{\left[\mathrm{B}_{\mathrm{u}}\right]-\alpha_{4}\left[\mathrm{~B}_{\mathrm{d}}\right]}{\left[\mathrm{B}_{\mathrm{u}}\right]+\alpha_{4}\left[\mathrm{~B}_{\mathrm{d}}\right]+\alpha_{3}\left([\mathrm{~B}]_{0}-\left[\mathrm{B}_{\mathrm{u}}\right]-\left[\mathrm{B}_{\mathrm{d}}\right]\right)}\left\{-1+\sqrt{1+\alpha_{2} e^{a, s}}\right\}
$$

\section{Limiting case}

Under high levels of irradiation, $\alpha_{2} e_{s}^{a}>>1$, the term $\left\{-1+\sqrt{1+\alpha_{2} e^{a, s}}\right\} \cong\left(\sqrt{\alpha_{2}} \sqrt{e^{a, s}}\right)$. Therefore, Eqs. (A.19) and (A.21) will take the following simplified form

$$
\begin{aligned}
& r_{u}\left(\frac{\mathrm{CFU}}{\mathrm{s} \mathrm{cm}^{2}}\right)=-\alpha \frac{\left[\mathrm{B}_{\mathrm{u}}\right]}{\left[\mathrm{B}_{\mathrm{u}}\right]+\alpha_{4}\left[\mathrm{~B}_{\mathrm{d}}\right]+\alpha_{3}\left([\mathrm{~B}]_{0}-\left[\mathrm{B}_{\mathrm{u}}\right]-\left[\mathrm{B}_{\mathrm{d}}\right]\right)} \sqrt{e^{a, s}} \\
& r_{d}\left(\frac{\mathrm{CFU}}{\mathrm{s} \mathrm{cm}^{2}}\right)=\alpha \frac{\left[\mathrm{B}_{\mathrm{u}}\right]-\alpha_{4}\left[\mathrm{~B}_{\mathrm{d}}\right]}{\left[\mathrm{B}_{\mathrm{u}}\right]+\alpha_{4}\left[\mathrm{~B}_{\mathrm{d}}\right]+\alpha_{3}\left([\mathrm{~B}]_{0}-\left[\mathrm{B}_{\mathrm{u}}\right]-\left[\mathrm{B}_{\mathrm{d}}\right]\right)} \sqrt{e^{a, s}}
\end{aligned}
$$

where $\alpha=\alpha_{1} \sqrt{\alpha_{2}}$ 


\section{Nomenclature}

A incident energy absorbed, dimensionless

$\mathrm{A}_{\text {irr }} \quad$ Irradiated area, $\mathrm{cm}^{2}$

B Bacteria

$e^{a, s} \quad$ superficial rate of photon absorption, einstein $\mathrm{cm}^{-2} \mathrm{~s}^{-1}$

$F_{\lambda} \quad$ normalized spectral distribution of the lamp output power, dimensionless

I radiation intensity, einstein $\mathrm{cm}^{-2} \mathrm{~s}^{-1} \mathrm{sr}^{-1}$

$k \quad$ kinetic constant, $\mathrm{cm}^{2} \mathrm{~mol}^{-1} \mathrm{~s}^{-1}$

$K_{i} \quad$ equilibrium adsorption constant

$\ell \quad$ stoichiometric coefficient

$P_{a c t} \quad$ Total radiation power, einstein $\mathrm{s}^{-1}$

$q_{n} \quad$ net radiation flux, einstein $\mathrm{cm}^{-2} \mathrm{~s}^{-1}$

$r \quad$ superficial reaction rate for bacteria, $\mathrm{CFU} \mathrm{cm} \mathrm{cm}^{-2} \mathrm{~s}^{-1}$

$r_{g s} \quad$ superficial rate of electron-hole generation, $\mathrm{mol} \mathrm{cm} \mathrm{cm}^{-2} \mathrm{~s}^{-1}$

$R \quad$ incident energy reflected, dimensionless

RMSE root mean square error

$t \quad$ time, $\mathrm{s}$

$T \quad$ incident energy transmitted, dimensionless

$V \quad$ volume, $\mathrm{cm}^{3}$

$x \quad 1-\mathrm{D}$ coordinate, $\mathrm{cm}$

Greek letters 


$\begin{array}{ll}\alpha & \text { kinetic parameter, } \mathrm{cm}^{2} \mathrm{~s}^{-0.5} \text { einstein }^{-0.5} \\ \alpha_{1} & \text { kinetic parameter, } \mathrm{cm} \mathrm{s}^{-1} \\ \alpha_{2} & \text { kinetic parameter, } \mathrm{cm}^{2} \mathrm{~s} \text { einstein } \\ & \\ \alpha_{3} & \text { kinetic parameter, dimensionless } \\ \alpha_{4} & \text { kinetic parameter, dimensionless } \\ \bar{\Phi} & \text { wavelength averaged primary quantum yield, mol einstein }{ }^{-1} \\ \delta_{j} & \text { average thickness of the film } \\ \kappa & \text { napierian volumetric absorption coefficient, } \mathrm{cm}^{-1} \\ \lambda & \text { wavelength, nm } \\ \theta & \text { direction cosine of the ray for which the RTE is written } \\ & \end{array}$

Subscripts

$0 \quad$ indicates initial condition

ads relative to the adsorbed phase

d relative to damaged bacteria

f $\quad$ film of catalyst

g relative to glass

i relative to inactivated bacteria

$\mathrm{p} \quad$ relative to products of bacteria lysis

pi relative to products of bacteria lysis

$\mathrm{T} \quad$ relative to total surface 
$\lambda$ indicates a dependence on wavelength

\section{Superscripts}

$\mathrm{S}$

superficial value

$+\quad$ forward value

backward value

Special symbols

[ ] concentration of bacteria species in the bulk, $\mathrm{CFU} \mathrm{\textrm {cm } ^ { - 3 }}$

indicates averaged value over the wavelength range 
Table 1. Reaction scheme for the photocatalytic inactivation of bacteria in a wall reactor.

\begin{tabular}{|c|c|c|}
\hline STEP & REACTION & RATE \\
\hline Activation & $\mathrm{TiO}_{2} \stackrel{\mathrm{h} v}{\longrightarrow} \mathrm{TiO}_{2}+\mathrm{e}^{-}+\mathrm{h}^{+}$ & $r_{g s}$ \\
\hline Recombination & $\mathrm{e}^{-}+\mathrm{h}^{+} \rightarrow$ heat & $v_{\mathrm{i}} k_{2}\left[\mathrm{e}^{-}\right]\left[\mathrm{h}^{+}\right]$ \\
\hline Electron trapping & $\mathrm{e}^{-}+\mathrm{O}_{2} \rightarrow \cdot \mathrm{O}_{2}^{-}$ & $v_{\mathrm{i}} k_{3}\left[\mathrm{e}^{-}\right]\left[\mathrm{O}_{2}\right]$ \\
\hline Hole trapping & $\mathrm{h}^{+}+\mathrm{H}_{2} \mathrm{O} \rightarrow \cdot \cdot \mathrm{OH}+\mathrm{H}^{+}$ & $v_{\mathrm{i}} k_{4}\left[\mathrm{~h}^{+}\right]\left[\mathrm{H}_{2} \mathrm{O}\right]$ \\
\hline \multirow[t]{9}{*}{ Hydroxyl attack } & $\mathrm{B}_{\mathrm{u}, \mathrm{ads}}+\ell \cdot \mathrm{OH} \rightarrow \mathrm{B}_{\mathrm{d}}$ & $v_{i} k_{5}[\cdot \mathrm{OH}]^{\ell}\left[\mathrm{B}_{\mathrm{u}, \mathrm{ads}}\right]$ \\
\hline & $\mathrm{B}_{\mathrm{d}, \mathrm{ads}}+\ell \cdot \mathrm{OH} \rightarrow \mathrm{B}_{\mathrm{i}}$ & $v_{i} k_{6}[\cdot \mathrm{OH}]^{\ell}\left[\mathrm{B}_{\mathrm{d}, \mathrm{ads}}\right]$ \\
\hline & $\mathrm{B}_{\mathrm{i}, \mathrm{ads}}+\ell \cdot \mathrm{OH} \rightarrow \mathrm{B}_{\mathrm{p} 1}+\mathrm{B}_{\mathrm{p} 2}+\ldots \mathrm{B}_{\mathrm{pi}} \ldots+\mathrm{B}_{\mathrm{pn}}$ & $v_{i} k_{7}[\cdot \mathrm{OH}]^{\ell}\left[\mathrm{B}_{\mathrm{i}, \mathrm{ads}}\right]$ \\
\hline & $\mathrm{B}_{\mathrm{p} 1, \mathrm{ads}}+\ell \cdot \mathrm{OH} \rightarrow$ Products & $v_{i} k_{81}[\cdot \mathrm{OH}]^{\ell}\left[\mathrm{B}_{\mathrm{p} 1, \mathrm{ads}}\right]$ \\
\hline & $\mathrm{B}_{\mathrm{p} 2 \text {,ads }}+\ell \cdot \mathrm{OH} \rightarrow$ Products & $v_{i} k_{82}[\cdot \mathrm{OH}]^{\ell}\left[\mathrm{B}_{\mathrm{p} 2, \mathrm{ads}}\right]$ \\
\hline & $\ldots$ & $\ldots$ \\
\hline & $\mathrm{B}_{\mathrm{pi}, \mathrm{ads}}+\ell \cdot \mathrm{OH} \rightarrow$ Products & $v_{i} k_{8 i}[\cdot \mathrm{OH}]^{\ell}\left[\mathrm{B}_{\mathrm{pi}, \mathrm{ads}}\right]$ \\
\hline & $\cdots$ & $\cdots$ \\
\hline & $\mathrm{B}_{\mathrm{pn}, \mathrm{ads}}+\ell \cdot \mathrm{OH} \rightarrow$ Products & $v_{i} k_{8 n}[\cdot \mathrm{OH}]^{\ell}\left[\mathrm{B}_{\mathrm{pn}, \mathrm{ads}}\right]$ \\
\hline \multirow[t]{4}{*}{ Adsorption } & $\mathrm{B}_{\mathrm{u}}+\mathrm{TiO}_{2}$ site $\leftrightarrow \mathrm{B}_{\mathrm{u}, \text { ads }}$ & $K_{u}$ \\
\hline & $\mathrm{B}_{\mathrm{d}}+\mathrm{TiO}_{2}$ site $\leftrightarrow \mathrm{B}_{\mathrm{d}, \mathrm{ads}}$ & $K_{d}$ \\
\hline & $\mathrm{B}_{\mathrm{i}}+\mathrm{TiO}_{2}$ site $\leftrightarrow \mathrm{B}_{\mathrm{i}, \text { ads }}$ & $K_{i}$ \\
\hline & $\mathrm{B}_{\mathrm{p}}+\mathrm{TiO}_{2}$ site $\leftrightarrow \mathrm{B}_{\mathrm{p}, \mathrm{ads}}$ & $K_{p}$ \\
\hline
\end{tabular}

